\title{
CANAL WALL DOWN MASTOIDECTOMY-DOCTOR DEPENDENT FOR WHOLE LIFE?
}

\author{
Amit Bikram Maiti1, Mukulika Saha², Somnath Patra3 ${ }^{3}$,Mayur Nair 4 , Pushpak Das 5 , Puspendu Bikas Mondal \\ ${ }^{1}$ RMO-Cum-Clinical Tutor, Department of Otorhinolaryngology, Midnapore Medical College, West Bengal, India. \\ ${ }^{2} 3^{\text {rd }}$ Year Post Graduate Trainee, Department of Otorhinolaryngology, Midnapore Medical College, West Bengal, India. \\ ${ }^{32}$ nd Year Post Graduate Trainee, Department of Otorhinolaryngology, Midnapore Medical College, West Bengal, India. \\ ${ }_{41}^{\text {st }}$ Year Post Graduate Trainee, Department of Otorhinolaryngology, Midnapore Medical College, West Bengal, India. \\ $5 J u n i o r$ Resident, Department of Otorhinolaryngology, Midnapore Medical College, West Bengal, India. \\ ${ }^{6}$ Medical Officer, Department of Otorhinolaryngology, Midnapore Medical College, West Bengal, India.
}

\begin{abstract}
Attico-antral pathology including cholesteatoma are treated by two surgical approaches like canal wall down and canal wall up mastoidectomy. Many literatures have published comparing merits and demerits of these two procedures. But, few literatures in the world describes the burden of patients as well as hospitals in terms of resources (money and manpower) needed after canal wall down mastoidectomy. In this study, we describe the outpatient attendance of patients after canal wall down mastoidectomy.
\end{abstract}

\section{MATERIALS AND METHODS}

This is a retrospective study. Total 81 cases of canal wall down mastoidectomy cases with preoperative diagnosis of cholesteatoma, non-cholesteatomatous CSOM, and malignant otitis externa were selected for this study. The main things were searched for frequency of visits, chronic cavity problems, and number of patients discharged during followup. In this study, all operations were conducted between June 2009 to July 2014 and followup was done up to January 2016.

\section{RESULT}

The patients in this study made a total number of 968 visits in outpatient department between June 2009 up to January 2016. Average visit per patient was 11.95 and interval between two visits per patient was an average of 6.52 months. About $63 \%$ of the patients are still attending outpatient department. The commonest causes for which canal wall down mastoidectomy patient attend outpatient department are chronic cavity inflammations, residual or recurrent cholesteatoma, structural cavity problems, and residual perforation.

\section{CONCLUSION}

Canal wall down mastoidectomy itself carries some intrinsic morbidity, which result in frequent outpatient visit.

\section{KEYWORDS}

Canal Wall Down Mastoidectomy, Canal Wall Up Mastoidectomy, Cholesteatoma, Mastoidectomy Complication.

HOW TO CITE THIS ARTICLE: Maiti AB, Saha M, Patra S, et al. Canal wall down mastoidectomy-doctor dependent for whole life?. J. Evolution Med. Dent. Sci. 2016;5(63):4415-4418, DOI: 10.14260/jemds/2016/1009

\section{INTRODUCTION}

Chronic suppurative otitis media is known to cause many intracranial and extracranial complications. ${ }^{1}$ CSOM are of two types, mucosal variety and attico-antral variety. In general teaching, it is commonly said that mucosal variety is safe type and attico-antral variety is unsafe type as it commonly harbour cholesteatoma. But, in contrast to this thought, Rupa and Raman found that patients who had complications due to CSOM were suffering from short duration of ear disease and were more likely had central perforation (Mucosal disease). ${ }^{2}$

Generally, two surgical approaches Canal Wall UP (CWU) and Canal Wall Down (CWD) mastoidectomy have been performed in CSOM with attico-antral disease. Many literatures describe the advantages and disadvantages of both surgical techniques. A study was done by Hulka and McElveen (1998) suggested that Canal Wall Down (CWD) mastoidectomy is superior than Canal Wall Up (CWU)

Financial or Other, Competing Interest: None.

Submission 18-06-2016, Peer Review 23-07-2016,

Acceptance 29-07-2016, Published 05-08-2016.

Corresponding Author:

Dr. Amit Bikram Maiti,

Flat No. 5FFF, Block K,

SD Tower, $A A-101$,

Prafullakanan (West), Krishnapur,

P. S. Baguihati, Kolkata-700101,

E-mail: amitent2004@gmail.com

DOI: $10.14260 /$ jemds/2016/1009 technique for visualisation of middle ear pathology. ${ }^{3}$ Many authors do not find any difference in postoperative outcome between canal wall up and canal wall down mastoidectomy. Merchant et al (1997) found that outcome was not dependent upon CWU versus CWD mastoidectomy, primary or revision surgery, and the extent of disease. 4

Many studies had done in past on different topics of CSOM. But, only few studies have done to address the work load due to repeated followup in outpatient department. This repeated followup leads to loss in terms of money and manpower. In this study, we report the outpatient attendance of canal wall down mastoidectomy patients in Midnapore Medical College.

\section{MATERIALS AND METHODS}

Cases were selected from hospital records. Total 81 cases with preoperative diagnosis of cholesteatoma, noncholesteatomatous CSOM and malignant otitis externa were selected for this study. All the patients selected for this study had no history of diabetes tuberculosis or any immune suppressive disease preventing wound healing. Routine postauricular incision was given with temporalis fascia harvested from same incision. Total clearance of cholesteatoma and granulation tissue from middle ear cleft with adequate lowering of facial bridge was done. Underlay temporalis fascia grafting over stapes head was done with adequate chonchomeatoplasty. 
All surgeries was performed by oto surgeons having experience of 10 to 25 years. In the records, it shows that patients were admitted for 7 days after operation and stitches were removed before discharge. First postoperative visit generally done 3 weeks after discharge.

The Standard Postoperative Followup Protocol in our Institution for Mastoidectomy as follows

$1^{\text {st }}$ visit: 4 weeks after operation.

$2^{\text {nd }}$ visit: 8 weeks after operation.

$3^{\text {rd }}$ visit: 12 weeks after operation.

Then, every 2 months for 2 visits 6 monthly for 2 years after operation and once annually/if any complication develops, patients were followed up as how many times he or she was coming to OPD and it was noted properly (Date of visit). During this postoperative visit, following findings like discharge, crust/debris, granulations, residual perforation, decreased hearing, balance problem, cholesteatoma, high facial ridge, and small meatus were noted carefully. This study was conducted in Midnapore Medical College from June 2009 to July 2014 (Operation done during this period) and followup was done up to January 2016.

\section{RESULT AND ANALYSIS}

Among 81 patients selected for study, 45 were male and 36 were female. Mean age of the patients under study was 28.17 years with age ranging from 7 to 65 years.

Fig. 1: Show the diagnosis of patients who underwent canal wall down mastoidectomy operation. 71 (87.65\%) patients had cholesteatoma either limited to attic region or in any space in middle ear cleft. In some other cases, there were extensive cholesteatoma involving mesotympanum, attic, and mastoid air cell system. 8 (9.87\%) patients had non-cholesteatomatous chronic suppurative otitis media, not responding to intensive and protracted conservative medical management. Other 2 patients $(2.46 \%)$ had diabetes mellitus and malignant otitis externa, not responding to conservative medical management.

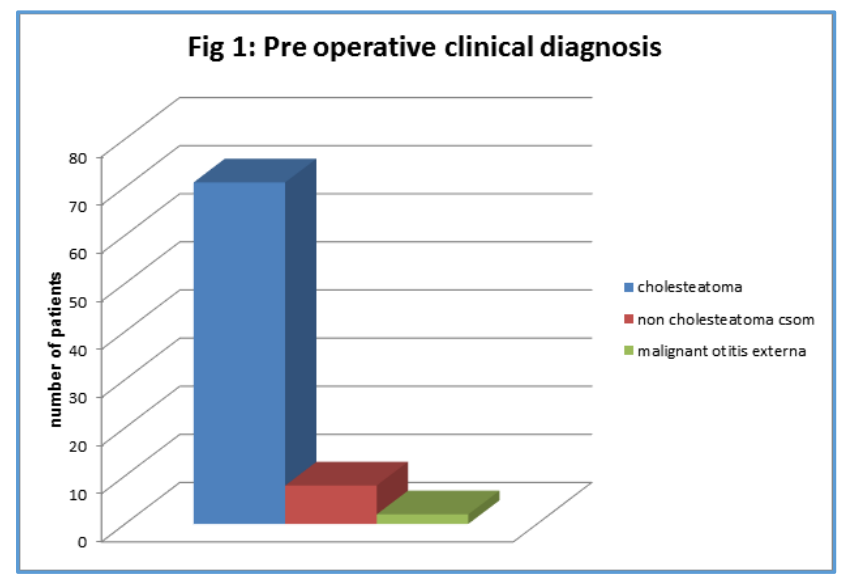

Fig. 2: Shows the current clinical status of patients. This figure shows 51 patients (62.96\%) still attending OPD. 20 patients (24.69\%) were discharged. They were advised no need for followup as they were cured from disease. 3 patients $(3.70 \%)$ moved away, one patient changed the residence from current places, 5 patients $(6.17 \%)$ did not attend for followup. During this study, 2 patients (2.46\%) lost their lives due to old agerelated illness. Three patients developed complications in postoperative period. One patient developed haematoma in postauricular region, which was drained subsequently. One patient developed postoperative wound infection with partial wound dehiscence and it was treated with appropriate antibiotic according to culture and sensitivity report. One patient developed Gr. 3 facial palsy, which subsequently returned to normal within 2 weeks.

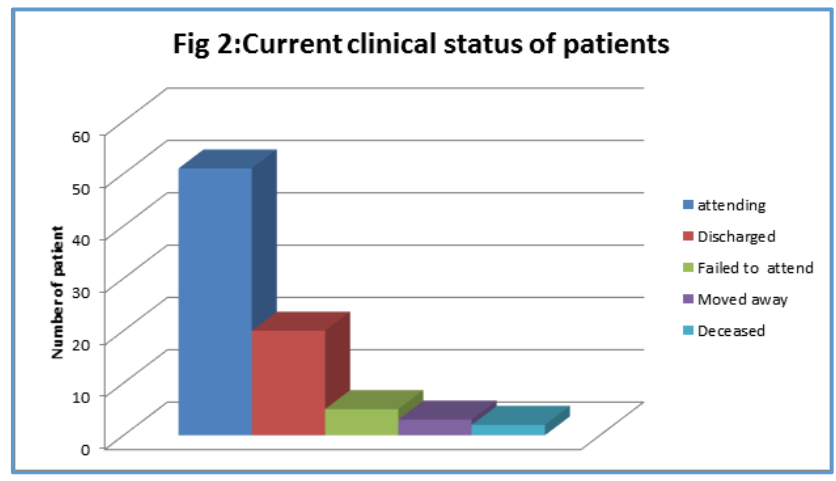

In this study, there were total 968 visits in outpatients department between June 2009 to January 2016. Average OPD visit per patient was 11.95. This chart has structured in chronological order so that first patient is earliest in operative series. (Fig.3).

Fig 3:Total number of OPD visits for each patients

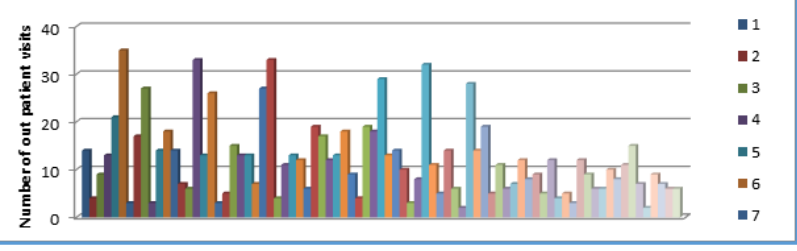

Fig. 4: Shows clinical findings in each postoperative outpatient visit. In this figure, it is shown that most common cause of postoperative visit is chronic cavity inflammation. This chronic cavity inflammation leads to different problems like wax, keratin accumulation, debris, discharge, and granulation tissue formation. Except balance problems, other findings (High facial ridge, small meatus) were recorded only once. 15 patients (18.51\%) had revision surgery (Fig. 5). Among these, obliteration of mastoid cavity was done in 2 patients. 2 patients underwent split thickness graft application and 1 patient had obliteration of Eustachian tube orifice. The remaining 10 patients underwent re-exploration of mastoid cavity for identifying the main area giving rise to cavity problem. These problems were high facial ridges, inadequate meati, and tympanic segment perforation. 2 patients were eventually discharged from OPD and remaining 8 patients were attending annual reviews, which is an indication for early manageable cavity. 

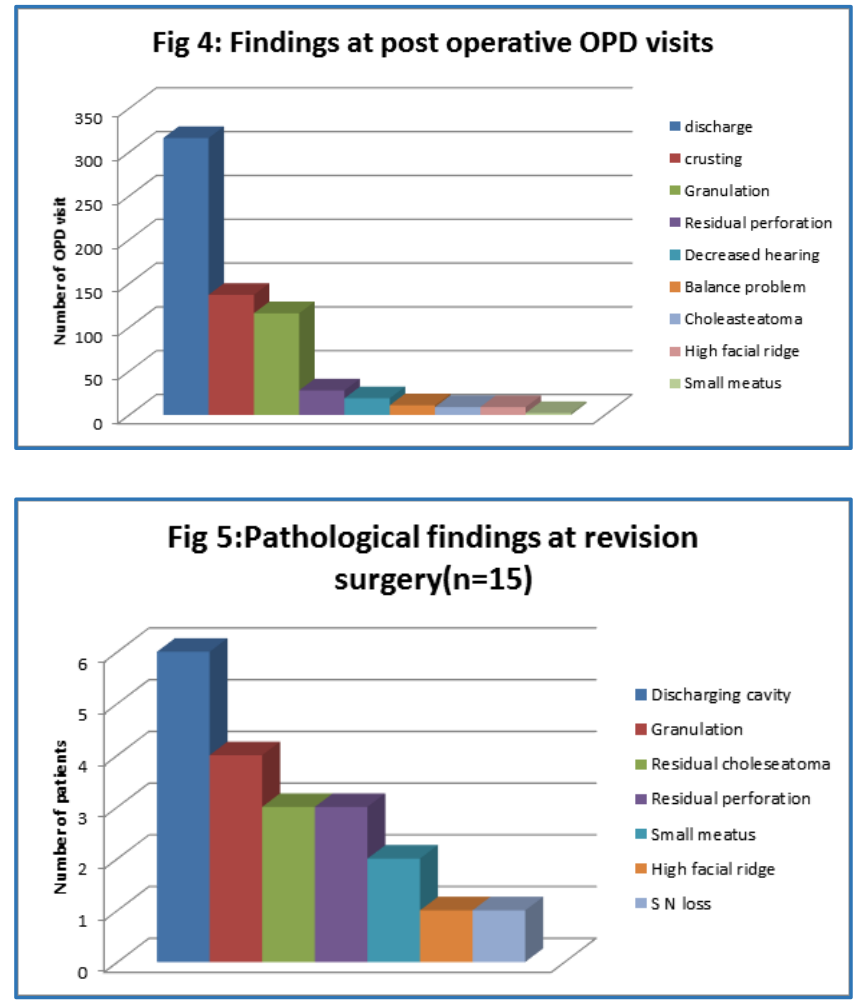

\section{DISCUSSION}

Choice of treatment in chronic discharging ear not responding to long-term medical treatment is surgical. In our study series, except few, most patients were suffering from cholesteatoma in various places of middle ear cleft. All the patients in our study underwent canal wall down mastoidectomy. Some authors prefer canal wall up mastoidectomy as hearing threshold are worse after canal wall down mastoidectomy. ${ }^{5}$ But, Karmakar et al found no difference in postoperative hearing result in canal wall down mastoidectomy and intact canal wall procedure. ${ }^{6}$ Toner and Smith in their study reported that postoperative hearing result was better one year after surgery in intact canal wall mastoidectomy than canal wall down mastoidectomy, but in long-term follow up, there is no significant difference between the two groups. ${ }^{7}$

Canal wall down mastoidectomy is very safe procedure when properly performed. In some centres, facial nerve monitor is routinely used for mastoid surgery, but it is not available in our centre rather we are dependent on our knowledge of anatomy of intratemporal course of facial nerve. In our series, there was no major complication except 1 patient developed grade 3 facial nerve paralysis, which subsequently returned to normal within 2 weeks. In operative technique, both the techniques like outside inwards (Cortical mastoidectomy converted into modified radical) and inside out mastoidectomy were performed and all efforts were made to make the cavity smaller. Smith and Brooker showed the technique of making small mastoid cavity compared to large cavity after modified radical mastoidectomy, but there was no difference in frequency of discharge between large and small cavity. ${ }^{8}$ National comparative audit of 611 mastoidectomy were published by Royal College of Surgeon of England in 1995.

In this published literature showed that number of wet ear is greater in canal wall down mastoidectomy than canal wall up mastoidectomy. ${ }^{9}$ Youngs studied the histological features of material from revision cases of mastoidectomy. Their findings include foreign body granuloma, squamous epithelium with acute and chronic inflammation, aural polyp. One important finding is frequent presence of pseudostratified ciliated columnar epithelium (Respiratory epithelium) in discharging ear suggesting that retained mucosa in the middle ear cleft is not a common cause of persistent otorrhea. 10

The most common findings in our study were due to chronic cavity problems like discharging cavities, crust, wax, and granulations. These problems are inherent to mastoid cavity and occur in most patients with mastoid cavity and not dependent upon how properly mastoid cavity is fashioned. The aims of postoperative followup are inspection of mastoid cavity, taking corrective measures, to keep epithelial lining of the cavity healthy, and to assess any remote chance of developing any complication. During the postoperative visits, mastoid cavities are cleaned properly to remove debris wax etc. by suction and sometimes under microscope. Granulations were cauterised by silver nitrate, antibiotic-steroid drop were applied in presence of infected cavity. When there were residual/recurrent cholesteatoma, perforation of the newlyformed tympanic membrane or fixed anatomical defect like high facial ridge, small meatus were readily taken to operation theatre for necessary correction (Definitive surgery). But, these numbers are very small.

The main question arises what is the correct interval between the followup. In some patients, cavities are rapidly well epithelised and within 1 year they have well epithelised dry lining cavity, which rarely need any cleaning. These patients can readily be discharged. Other group of patients have granular myringitis. Very small number of patients fall in this group. Most of the patients fall in the third group where most of the time ear is dry, intermittently moist. Another group of patients who remained status quo with regular aural toileting at long interval. There is no definite predictive factor for radical mastoidectomy, but limited cholesteatoma in attic with normal-appearing pars tensa and normal functioning eustachian tube bear good prognosis.

Sade in his publication in 2000 on surgical planning of the treatment of cholesteatoma and postoperative followup showed that average followup interval for well-established cavity was on average 5 months. ${ }^{11}$ In our study, average time interval between two consecutive postoperative visit is 6.52 months.

In our series, there were 81 patients among them 51 $(62.96 \%)$ still attending the OPD. This signifies that significant number of patients who underwent canal wall down mastoidectomy require long-term patient care in followup period. Every patient requires few minutes time to be examined in OPD. When number of followup patients increases, total time taken in OPD is much increased. This causes huge work load in OPD and loss of money and working days of patients also especially in first 1-2 years of surgery. In our operative series, only one quarter $(24.69 \%)$ of patients have been discharged. With subsequent years, more number of patients will attend OPD for followup.

Canal wall down mastoidectomy is the most preferred surgery all over the world for long time. However, there is increasing trends among otologist to practice canal wall up technique. From our studies, it is very apparent that canal wall down mastoidectomy causes significant workload in our OPD especially in first 24 months after surgery. Immediate and long-term follow-up is generally is more intense in canal wall 
down mastoidectomy cases as debridement is needed in many cases. In contrast, in canal wall up surgery where ear maintain normal anatomy heals quickly and less followup needed. Toner et al challenged this view in their study where surgery for cholesteatoma carried out between the ages 8 and 12 years. They found no significant difference in followup interval between in canal wall down and canal wall up surgery. ${ }^{7}$

More difficult issue is addressed regarding the wellbeing of patients in canal wall up and canal wall down mastoidectomy surgery. There is increasing interest in different part of the world concerning the validation of outcome of treatment modalities. Some recent publications have emphasised to take notes on the outcome of surgery in terms of technical success and also in term of impact of treatment upon patient lifestyle and wellbeing. ${ }^{12}$ Canal wall down and canal wall up, both the procedure carry some intrinsic morbidity and in some frail patients this prevent to take definitive surgical treatment, which is appropriate in this case. Similarly, staged surgery of canal wall up procedure prevent this technique for elderly or infirm patients. It is necessary for the surgeon to explain preoperatively the patient and the relatives about the strategy of treatment outcome and morbidity, which may arise after surgery.

\section{CONCLUSION}

The decision to manage chronic suppurative otitis media with cholesteatoma by canal wall down mastoidectomy should be taken very seriously after concerning all aspect of it. Postoperative patients will be under regular followup for long time. When the cavity will be dry and free from all cavity problems and attend self-cleaning property after several visits patient can be discharged.

\section{REFERENCES}

1. Samuel J, Fernandes CM, Steinberg JL. Intracranial otogenic complications: a persistent problem. Laryngoscope 1986;96(3):272-8.
2. Rupa V, Raman R. Chronic suppurative otitis media: complicated versus uncomplicated disease. Acta Otolaryngol 1991;111(3):530-5.

3. Hulka GF, McElveen JT. A randomised blinded study of canal wall up versus canal wall down mastoidectomy determining the differences in viewing middle ear anatomy and pathology. Am J Otol 1998;19(5):574-8.

4. Merchant SN, Wang $\mathrm{P}$, Jang $\mathrm{CH}$, et al. Efficacy of tympanomastoid surgery for control of infection in active chronic otitis media. Laryngoscope 1997;107(7):872-7.

5. Tos M, Lau T. Hearing after surgery for cholesteatoma using various techniques. Auris Nasus Larynx 1989; 16(2):61-73.

6. Karmakar S, Bhatia S, Saleh E, et al. Cholesteatoma surgery: the individual technique. Annals of Otology, Rhinology, and Laryngology 1995;104(8):591-5.

7. Toner JG, Smyth GD. Surgical treatment of cholesteatoma: a comparison of three techniques. American Journal of Otology 1990;11(4):247-9.

8. Smyth GDL, Brooker DS. Small cavity mastoidectomy. Clinical Otolaryngology and Allied Sciences 1992;17(3): 280-3.

9. Harkness P, Brown PM, Fowler S, et al. Mastoidectomy audit: results of the Royal College of Surgeons of England comparative audit of ENT surgery. Clin Otolaryngol Allied Sci 1995;20(1):89-94.

10. Youngs R. The histopathology of mastoidectomy cavities with particular reference to persistent disease leading to chronic otorrhoea. Clin Otolaryngol and Allied Sciences 1992;17(6):505-10.

11. Sadé J. Surgical planning of the treatment of cholesteatoma and postoperative followup. Ann Otol Rhinol Laryngol 2000;109(4):372-6.

12. Wang PC, Nadol JB, Merchant S, et al. Validation of outcomes survey for adults with chronic suppurative otitis media. Ann Otol Rhinol Laryngol 2000;109(3): 249-54. 